\title{
Thiophene Chemistry
}

\section{XIV.* Thiomaleic Anhydride}

\section{JENS Z. MORTENSEN and SVEN-OLOV LAWESSON}

\section{Department of Organic Chemistry, Chemical Institute, University of Aarhus, 8000 Aarhus C, Denmark}

Tn recent years there has been great interest in the preparation of thiomaleic anhydride: Mayer et al. ${ }^{1}$ failed to prepare it, but according to a recent patent ${ }^{2}$ it was prepared in low yields by catalytic oxida. tion of thiophene. Quite recently ${ }^{3}$ it was also obtained, although in low overall yields, in a 2-step synthesis, starting from $\mathbf{4 , 5}, 8,9$-tetrahydrophthalic anhydride. In connection with our general studies of potential mono-, ${ }^{4}$ di-, ${ }^{5}$ and tri ${ }^{6}$-hydroxythiophenes we have found another method for the preparation of thiomaleic anhydride, which is described below. In forth-coming publications the scope of this reaction and the synthetic and spectroscopic investigations of the title compound will be published.

2,3,5-Tribromothiophene, I, is reacted with butyllithium at $-40^{\circ} \mathrm{C}$ to give 3,5 dibromothienyllithium, ${ }^{7}$ which is treated with anhydrous magnesium bromide, followed by $t$-butyl perbenzoate ${ }^{4}$ to give 2-t-butoxy-3,5-dibromothiophene, II. In the same way 2,5-di-t-butoxy-3-bromothiophene, III, is prepared from II. By heating III in the presence of catalytic

* Part XIII. J. H. Bowie, R. G. Cooks, S.-O. Lawesson, and C. Nolde, J. Chem. Soc. B 1967616.

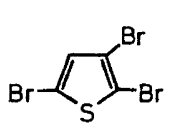

1) $\mathrm{Bu} \mathrm{Li}$

2) $\mathrm{MgBr}_{2}$

3) $\mathrm{C}_{6} \mathrm{H}_{5} \mathrm{CO}_{3} \mathrm{t}-\mathrm{Bu}$

1

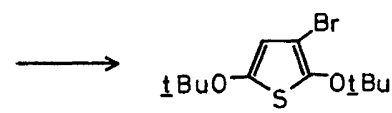

III amounts of $p$-toluenesulphonic acid, thiomaleic anhydride is isolated in $91 \%$ yields after isobutylene and $\mathrm{HBr}$-elimination. Physical constants of IV and also UV, IR, and NMR data were identical with earlier published ones. ${ }^{3}$

Experimental. 2-t-Butoxy-3,5-dibromothiophene, II. 3,5-Dibromothienyllithium was prepared from $130 \mathrm{~g}(0.41 \mathrm{~mole})$ of 2,3,5-tribromothiophene in $300 \mathrm{ml}$ of ether and $168 \mathrm{ml}(0.42$ mole) of butyllithium. ${ }^{7}$ Then 0.5 mole of anhydrous $\mathrm{MgBr}_{2}$ (prepared from $16.4 \mathrm{~g}$ of magnesium and $80 \mathrm{~g}$ of bromine in $200 \mathrm{ml}$ of ether) was added rapidly with stirring. After $75 \mathrm{~min}$, when the temperature had raised to zero, $65 \mathrm{~g}(0.33 \mathrm{~mole}, 60 \mathrm{ml})$ of $t$-butyl perbenzoate in $100 \mathrm{ml}$ of ether was added, during $30 \mathrm{~min}$, to the solution, kept at $0^{\circ} \mathrm{C}$. After stirring for another $4 \mathrm{~h}$ the mixture was worked up in the usual way. ${ }^{4}$ B.p. $90-91^{\circ} \mathrm{C} / 0.3$ $\mathrm{mm} \mathrm{Hg} ; n_{\mathrm{D}}{ }^{20}=1.5620$; yield: $98 \mathrm{~g}(95 \%)$. (Found: C 30.67; H 3.35; $\mathrm{Br} 50.94 ; \mathrm{S} 10.34$. Calc. for $\mathrm{C}_{8} \mathrm{H}_{10} \mathrm{OSBr}_{2}$ : C 30.57; $\mathrm{H} \mathrm{3.18;} \mathrm{Br}$ 50.96; S 10.19).

2,5-Di-t-butoxy-3-bromothiophene, III. The title compound was prepared as above from $72 \mathrm{~g}$ ( $0.25 \mathrm{~mole})$ of II and worked up as usual. B.p. $62-64^{\circ} \mathrm{C} / 0.1 \mathrm{~mm} \mathrm{Hg} ; n_{\mathrm{D}}{ }^{20}=1.5165$; yield: $59 \mathrm{~g}(90 \%)$. (Found: $\mathrm{C} 47.35$; H 5.88; Br 25.78. Calc. for $\mathrm{C}_{12} \mathrm{H}_{19} \mathrm{O}_{2} \mathrm{SBr}$ : $\mathrm{C} 46.97$; $\mathrm{H}$ 5.22; Br 26.38).

Thiomaleic anhydride, IV. III (crude product from above) was placed in a Vigreux distilla. tion set, heated with $5 \mathrm{mg}$ of $p$-toluenesulphonic acid at $110-120^{\circ} \mathrm{C}$ under vacuum. After isobutylene and $\mathrm{HBr}$-elimination has ceased, the product was distilled immediately. B.p. $68-70^{\circ} \mathrm{C} / 10 \mathrm{~mm} \mathrm{Hg}$; m.p. $\approx 26^{\circ} \mathrm{C}$ (lit. ${ }^{3}$; b.p. $72-74^{\circ} \mathrm{C} / 10 \mathrm{~mm} \mathrm{Hg}$; m.p. $\left.28^{\circ} \mathrm{C}\right) ; n_{\mathrm{D}}{ }^{30}=$ 1.5606. (Found: $\mathrm{C} 41.82 ; \mathrm{H}$ 1.83. Calc. for $\mathrm{C}_{4} \mathrm{H}_{2} \mathrm{O}_{2} \mathrm{~S}$ : C 42.12; $\mathrm{H}$ 1.77). UV: (hexane) $\lambda_{\max } 230,318(\varepsilon 9220,620)$. IR: $\left(\mathrm{CCl}_{4}\right) 1690$ (s), $1730(\mathrm{v})$. NMR: $\left(\mathrm{CDCl}_{3}\right)$ a single peak at 433 cps.

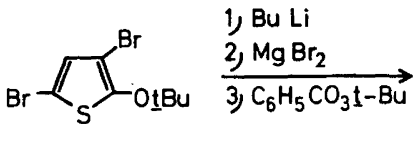

II

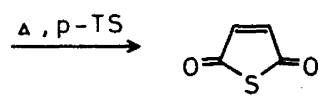

IV

Acta Chem. Scand. 22 (1968) No. 3 
1. Mayer, R., Daebritz, G., Ullrich, G., Werner, H., Ullricht, G. and Gewalt, $K$. J. prakt. Chem. 21 (1963) 80.

2. Jennings, T. J. (Shell Oil Co.) U.S.P. 3 265712 (August 9, 1966); Chem. Abstr. 65 (1966) 12113.

3. Sharf, H. D. and Verbeek, M. Angew. Chem. 79 (1967) 870 .

4. Jakobsen, H. J. and Lawesson, S.-O. Tetrahedron 23 (1967) 871 and refs. cited therein.

5. Mortensen, J. Z. and Lawesson, S.-O. To be published.

6. Nygaard, S.-P. and Lawesson, S.-O. To be published.

7. Lawesson, S.-O. Arkiv Kemi 11 (1957) 317.

Received March 28, 1968.

\section{An Electron Diffraction Study of Tetracyanoethylene HAKON HOPE}

\section{Department of Chemistry, University of California, Davis, California 95616, U.S.A.}

\section{$\mathbf{T}$} he crystal structure of monoclinic tetracyanoethylene (TCNE) was first reported by Bekoe and Trueblood.' They observed a rather short central $\mathrm{C}=\mathrm{C}$ distance of $1.317 \AA$ (e.s.d. $0.009 \AA$ ). Penfold and Lipscomb determined the structure of diaminomaleonitrile, ${ }^{2}$ and found the $C=C$ distance in that compound to be $1.363 \AA$ (e.s.d. $0.004 \AA$ ). According to the discussion by these authors there seems to be no obvious reason for the $\mathrm{C}=\mathrm{C}$ bonds to be so different in the two compounds. It was therefore felt to be of interest to study the structure of the TCNE molecule by the gas phase electron diffraction method.

Electron diffraction diagrams were recorded photographically with the sector method at nozzle to plate distances of about 12, 19, and $48 \mathrm{~cm}$, using an electron wavelength of about $0.065 \AA$. The intensity data were treated in the usual manner, ${ }^{3}$ giving a useful observed molecular intensity function for the range $s=1.25 \AA^{-1}$ to $s=55 \AA^{-1}$ from which a radial distribu. tion curve was computed.
A planar, symmetric molecular model with $\mathrm{C}-\mathrm{C} \equiv \mathrm{N}$ linear was fitted to the radial distribution curve by adjusting structural parameters to give the closest possible correspondence between experimental and theoretical radial distribution curves.

Table 1. Tetracyanoethylene. Interatomic distances and root-mean-square amplitudes of vibration.

\begin{tabular}{lll}
\hline Atoms & Distance & R.m.s. amplitude \\
\hline$C(1)-C(2)$ & $1.357 \AA$ & $0.046 \AA$ \\
$C(1)-C(3)$ & 2.430 & 0.060 \\
$C(1)-N(4)$ & 3.495 & 0.120 \\
$C(1)-C(9)$ & 1.435 & 0.047 \\
$C(1)-N(10)$ & 2.597 & 0.060 \\
$C(3)-N(4)$ & 1.162 & 0.035 \\
$C(3)-C(5)$ & 2.460 & 0.090 \\
$C(3)-N(6)$ & 3.515 & 0.120 \\
$C(3)-C(7)$ & 3.754 & 0.074 \\
$C(3)-N(8)$ & 4.871 & 0.089 \\
$C(3)-C(9)$ & 2.835 & 0.097 \\
$C(3)-N(10)$ & 3.575 & 0.120 \\
$N(4)-N(6)$ & 4.452 & 0.144 \\
$N(4)-N(8)$ & 5.980 & 0.096 \\
$N(4)-N(10)$ & 4.030 & 0.192 \\
$\angle C(1)-C(2)-C(3)$ & & $121.1^{\circ}$ \\
\hline
\end{tabular}

The molecular dimensions and corresponding root-mean-square amplitudes of vibrations are listed in Table 1, with the numbering system indicated in Fig. 1.

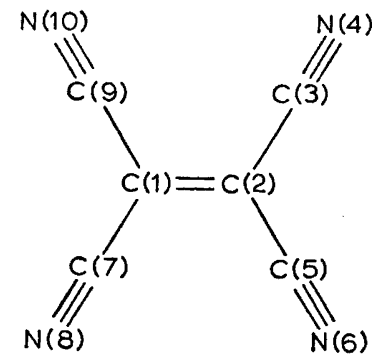

Fig. 1. Molecular model for tetracyanoethylene with indication of numbering system used.

The parameters in Table 1 were used in the calculation of the theoretical intensity curve shown in Fig. 2(b), and in the theoretical radial distribution curve in Fig. $3(b)$ (a damping function $\exp \left(-0.0009 s^{2}\right.$ ) was used for the curves in Fig. 3). 